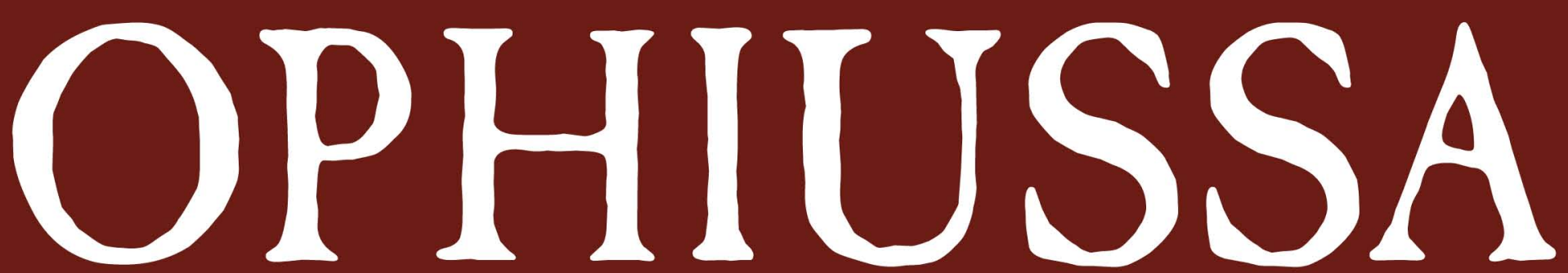

REVISTA DO CENTRO DE ARQUEOLOGIA DA UNIVERSIDADE DE LISBOA

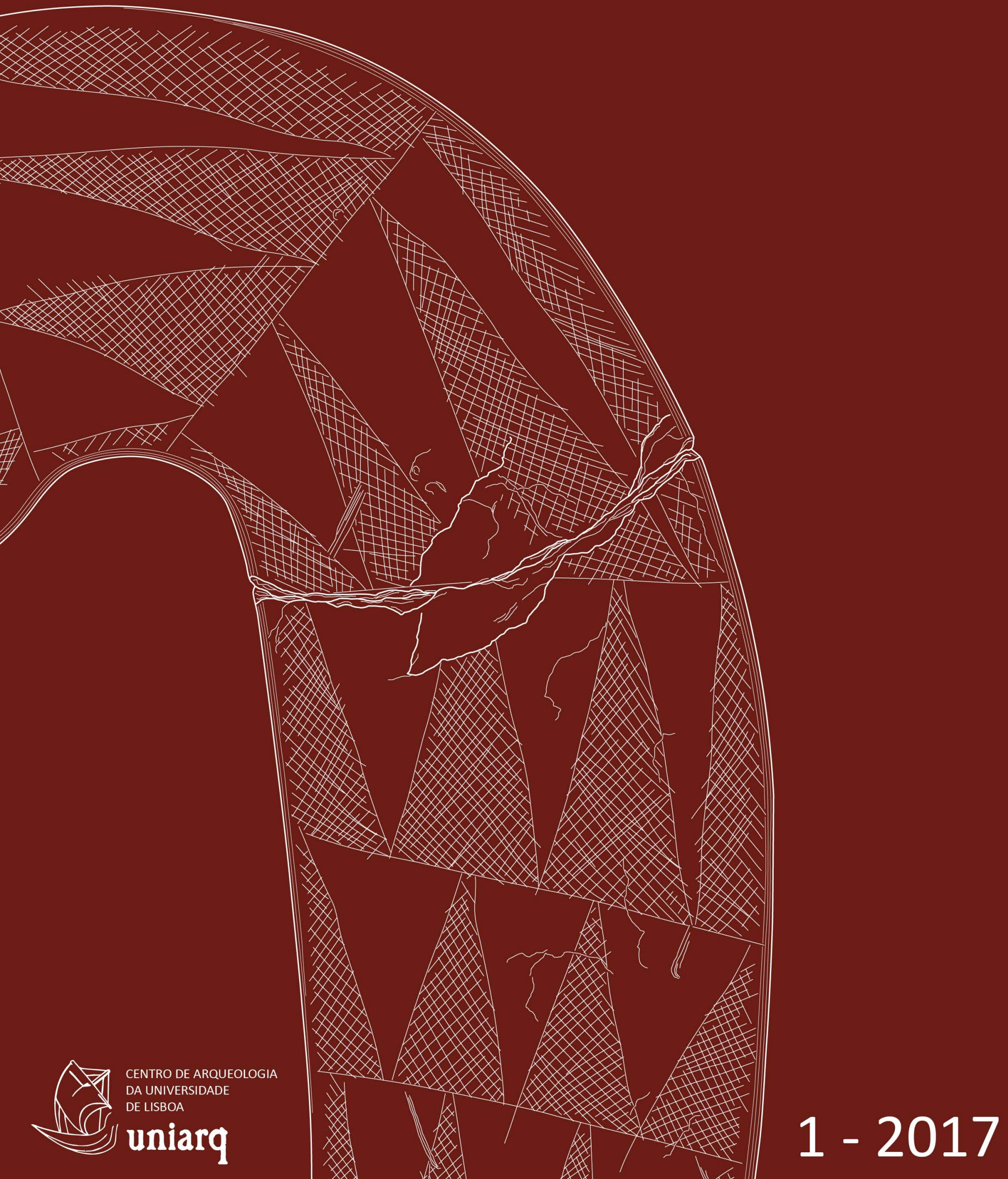


OPHIUSSA. Revista do Centro de Arqueologia da Universidade de Lisboa

ISSN $1645-653 X$

Publicação anual

Volume 1 - 2017

Direcção e Coordenação Editorial:

Ana Catarina Sousa

Elisa Sousa

Rui Boaventura

Conselho Científico:

André Teixeira (Universidade Nova de Lisboa)

Carlos Fabião (Universidade de Lisboa)

Catarina Viegas (Universidade de Lisboa)

Gloria Mora (Universidad Autónoma de Madrid)

Grégor Marchand (Centre National de la Recherche Scientifique)

João Pedro Bernardes (Universidade do Algarve)

José Remesal (Universidade de Barcelona)

Leonor Rocha (Universidade de Évora)

Manuela Martins (Universidade do Minho)

Maria Barroso Gonçalves (Instituto Superior de Ciências do Trabalho e da Empresa)

Mariana Diniz (Universidade de Lisboa)

Raquel Vilaça (Universidade de Coimbra)

Xavier Terradas Battle (Consejo Superior de Investigaciones Científicas)

Secretariado: André Pereira

Capa: André Pereira sobre Báculo do Sobral do Martim Afonso (desenho de Marco Andrade).

Paginação: Elisa Sousa

Impressão: Europress

Data de impressão: Novembro de 2017

Edição impressa (preto e branco)

200 exemplares

Edição digital (a cores)

www.ophiussa.letras.ulisboa.pt

ISSN: $1645-653 X$

Depósito legal: 190404/03

Copyright $\odot 2017$, os autores

Edição:

UNIARQ - Centro de Arqueologia da Universidade de Lisboa

Faculdade de Letras de Lisboa

1600-214 - Lisboa

www.uniarq.net - www.ophiussa.letras.ulisboa.pt - uniarq@letras.ulisboa.pt

O cumprimento do acordo ortográfico de 1990 foi opção de cada autor. 


(I)

\title{
OPHIUSSA
}

Volume 1, 2017, páginas 79-90

\section{FENÍCIOS E INDÍGENAS EM CONTACTO NO ESTUÁRIO DO TEJO}

\author{
ANA MARGARIDA ARRUDA * \\ ELISA DE SOUSA ${ }^{* *}$ \\ JOÃO PIMENTA*** \\ RUI SOARES ${ }^{* *}$ \\ HENRIQUE MENDES **
}

\section{RESUMO}

A fase final da Idade do Bronze, no estuário do Tejo, é notavelmente dinâmica, traduzindo-se em habitats, necrópoles e depósitos votivos. A tipologia destas ocupações evidencia, aparentemente, uma organização hierarquizada, mesmo em contextos domésticos, com pequenos sítios implantados nas planícies e outros de maiores dimensões no topo das elevações. A ocupação é densa dentro do território, verificando-se em ambas as margens do rio, mas também em zonas mais interiores. $O$ início da Idade do Ferro (final do século VIII a.n.e.) acarretou uma nova situação. Muitos sítios foram abandonados no interior, e a ocupação humana passou a favorecer as planícies aluviais do Tejo. Aqui, os sítios de maior dimensão, como Santarém, Almaraz e Lisboa, absorveram a população oriental e tornaram-se os principais centros de poder. Provavelmente, foram também responsáveis pela fundação de novos estabelecimentos na margem esquerda, como é o caso do Cabeço da Bruxa e do Porto do Sabugueiro, e direita (Quinta da Marqueza) do rio.

Palavras-chave: Fenícios; Bronze Final; Estuário do Tejo; Padrões de povoamento.

\section{ABSTRACT}

In the estuary of the Tagus river a strong final Bronze Age is identified, with habitats, necropolis and votive deposits. The typology of the settlements shows an apparently hierarchized structure, even in domestic contexts, with small sites in the plains and larger ones in the top of hills. The occupation is dense in the territory, with an occupation in both rivers' borders, but also in the hinterland. The beginning of Iron Age (in the late VIII century b.c.e.) brought a new situation. Many sites were abandoned in the inland, and the occupation favors the occupation of the land banks of the river. Here, the large sites, like Santarém, Almaraz e Lisboa, absorbed eastern population, and became the centers of power. Probably they planed the foundation of new sites in the left river's banks, like Cabeço da Bruxa e Porto do Sabugueiro, and in the right (Quinta da Marqueza).

Keywords: Phoenicians; Late Bronze Age; Tagus estuary; Settlement patterns.

\footnotetext{
* - Universidade de Lisboa, Faculdade de Letras, Uniarq - Centro de Arqueologia da Universidade de Lisboa. a.m.arruda@letras.ulisboa.pt

** - Universidade de Lisboa, Faculdade de Letras, Uniarq - Centro de Arqueologia da Universidade de Lisboa / Fundação para a Ciência e a Tecnologia.e.sousa@campus.ul.pt; ruigusmao@hotmail.com

*** - Câmara Municipal de Vila Franca de Xira. joao.marques@cm-vfxira.pt; henrique.mendes@cm-vfxira.pt

Trabalho realizado no âmbito do Projecto Fenícios no Estuário do Tejo, financiado pela FCT PTDC/EPH-ARQ/4901/2012
} 


\section{INTRODUÇÃO}

O rio Tejo pode considerar-se como um espaço privilegiado de penetração na Península Ibérica, em grande parte à semelhança do Ebro. Dá, portanto, também acesso a um interior rico em metais, nomeadamente estanho. Contudo, as margens do seu estuário, nomeadamente a esquerda, também se destacam pela fertilidade dos terrenos, sendo o território dos actuais concelhos de Alpiarça, Almeirim e Salvaterra de Magos ainda hoje considerado uma das regiões mais ricas de toda a Península Ibérica do ponto de vista agrícola.

Não é pois surpreendente que tenha sido nas margens do seu estuário que o contacto com as comunidades mediterrâneas se tenha produzido, quer durante a Proto-História, quer, mais tarde, na época romana. De facto, se actualmente tudo indica que a primeira grande campanha militar programada na futura província da Lusitânia se dirigiu para o Tejo, também tudo indicia que a história fenícia no território actualmente português se iniciou neste mesmo espaço geográfico (Arruda 2005a; 2005b). A área do Estuário do Tejo é o espaço onde mais consistentemente se documentaram vestígios arqueológicos que comprovam a antiguidade dos contactos fenícios com o território actualmente português, o que está fundamentado nas datações radiométricas e em materiais arqueológicos concretos, em Santarém (Arruda 1993; 1999-2000; 2005a; 2005b) e em Lisboa (Pimenta - Calado - Leitão 2014; Pimenta - Silva - Calado 2014; Calado et al. 2013).

Essa mesma área estava, todavia, já ocupada, sendo que essa ocupação está atestada por um número considerável de sítios e de espólios, de natureza muito diversa. A chegada dos colonos fenícios não encontrou pois aqui uma terra de ninguém, um território vazio, um espaço despovoado. Pelo contrário, os habitats são numerosos, extensos e de tipologia variada, havendo também necrópoles, "depósitos" e outros espaços de funcionalidade mais difícil de interpretar.

\section{O BRONZE FINAL NO ESTUÁRIO DO TEJO}

A Estremadura portuguesa e o Ribatejo são regiões densamente povoadas durante o Bronze Final, assumindo o povoamento alguma variabilidade no que se refere à extensão e à implantação topográfica.

A existência de povoados fortificados que ocupam uma área extensa e que estão implantados em cotas altas está demonstrada. É, por exemplo, o caso de Santarém (Arruda - Sousa 2015), do Alto do Castelo de Alpiarça (Kalb - Höck 1982a; 1985; 1988), do Castro do Amaral (Alenquer) e possivelmente de Almaraz (Barros 1998), estes, como veremos, com continuidade na Idade do Ferro. Outros, porém, com idênticas condições topográficas serão abandonados no final da Idade do Bronze: Castelo dos Mouros, em Sintra (Cardoso 1997-1998), Cabeço de Alcainça (Ponce 2013) e Serra do Socorro (Matias 2004), em Mafra, Monte da Pena (Madeira et al. 1972), em Torres Vedras, Castelo da Amoreira (Marques 1987; Boaventura - Pimenta - Valles 2013), Loures e Castro da Ota (Barbosa 1956), em Alenquer. Outros casos há ainda, cuja informação é de tal forma escassa, que não nos atrevemos a avançar com qualquer classificação, de que é bom exemplo o Castro de Pragança (Vasconcellos 1915). A ocupação do Bronze Final deste sítio estremenho é indiscutível, estando materializada por um conjunto muito significativo de bronzes, de que destacamos os ponderais (Vilaça 2003) e um fragmento com decoração entrançada (Lopes - Vilaça 1998; Vilaça 2007). Contudo, e havendo notícia de materiais da Idade do Ferro, não existem dados suficientes para perceber qual a sua cronologia exacta.

Sítios sem condições naturais de defesa e de visibilidade reduzida, com áreas de ocupação mais restritas foram também registados, como são os casos, entre outros, da Tapada da Ajuda (Cardoso et al. 1980-1981; Cardoso - Silva 2004), em Lisboa, e dos Moinhos da Atalaia (Pinto - Parreira 1978), na Amadora.

Estamos pois perante um povoamento hierarquizado, em que os sítios de menores dimensões, localizados nos vales das ribeiras que se incluem na bacia hidrográfica do Tejo, estavam vocacionados para a prática de actividades agrícolas e pecuárias (Vilaça - Arruda 2004).

Porém, o tipo de estruturas construídas não difere entre uns e outros, dominando as plantas ovais, nas construções domésticas (por exemplo na Tapada da Ajuda), construções que incluem ainda empedrados de planta circular, detectados em Lisboa (Silva 2013) e na Quinta Nova de Santo António (Neto et al. 2013), em Carcavelos.

Em ambos, a cerâmica manual de superfícies apenas alisadas ou polidas é a mais frequente, havendo a registar fragmentos decorados, quer com retícula brunida, quer com incisões, alguns destes últimos incluídos no chamado tipo Cogotas, que, contudo, são sempre minoritários e foram apenas 


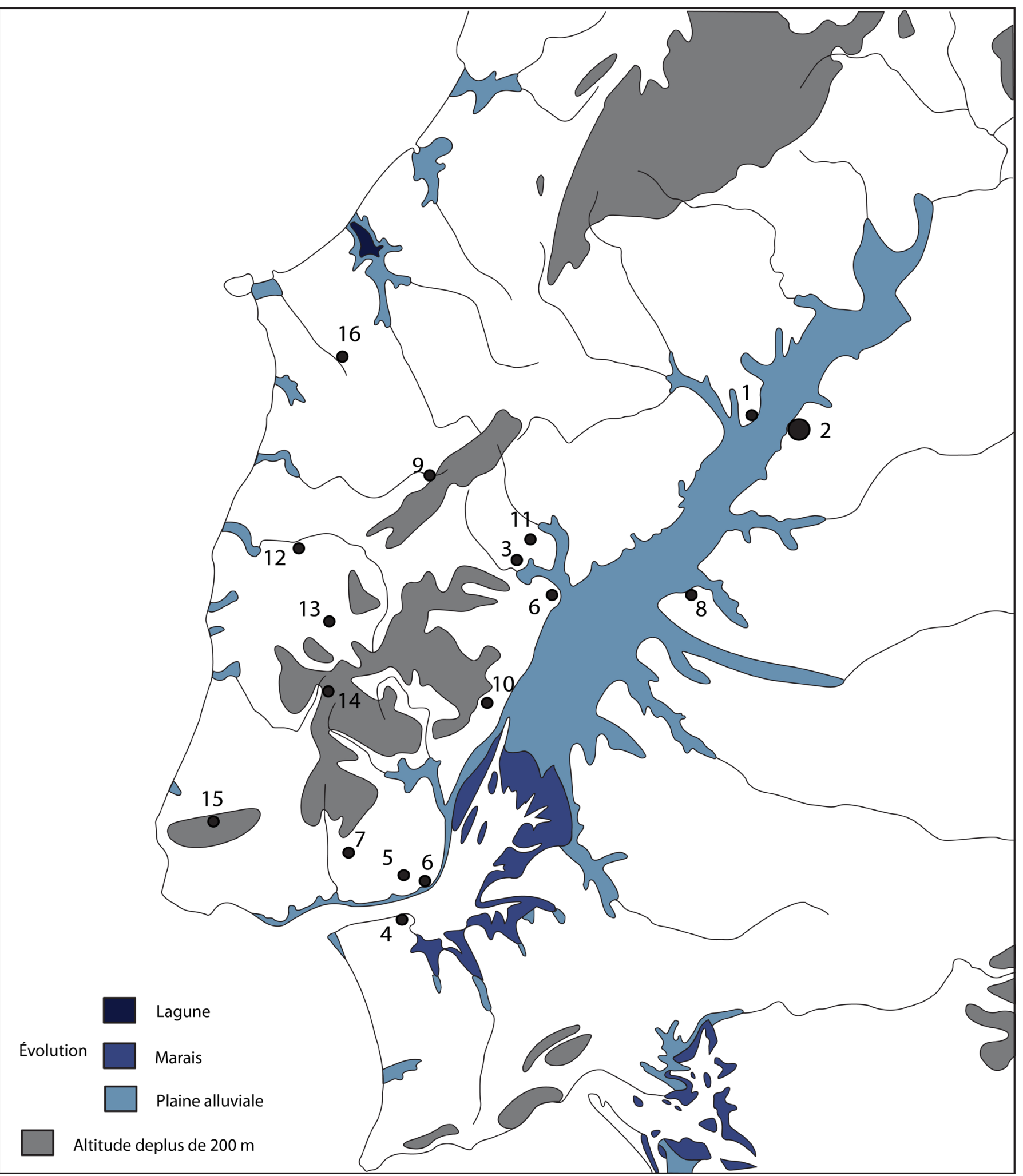

Fig. 1 - Ocupação do Bronze Final no estuário do Tejo: 1 - Santarém; 2 - Alto do Castelo e necrópoles de Alpiarça (Cabeço da Bruxa, Tanchoal, Meijão); 3 - Castro do Amaral; 4 - Almaraz; 5 - Tapada da Ajuda; 6 - Lisboa; 7 - Moinhos da Atalaia; 8 Escaroupim; 9 - Pragança; 10 - Moita da Ladra; 11 - Castro da Ota; 12 - Monte da Pena; 13 - Serra do Socorro; 14 - Cabeço de Alcainça; 15 - Castelo dos Mouros; 16 - Fiéis de Deus. 


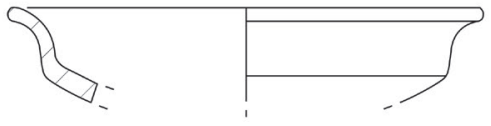

184 [294]

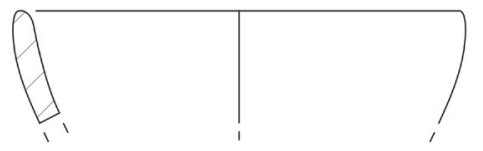

161 [310]

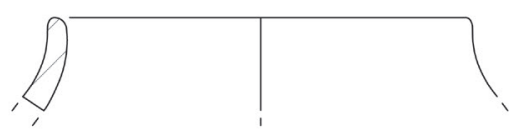

166 [308]

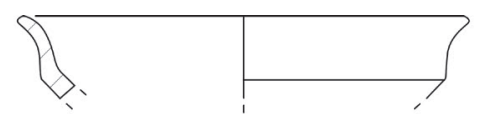

183 [294]

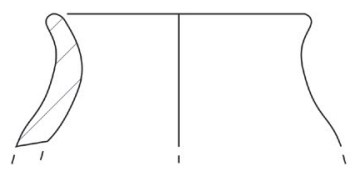

170 [294]

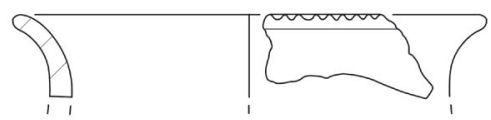

$158[310]$

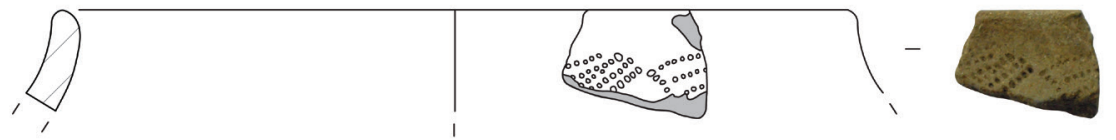

83 [317]

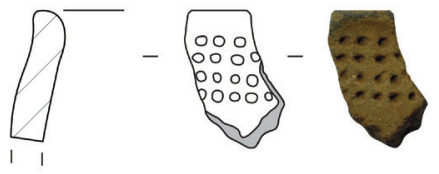

130 [317]

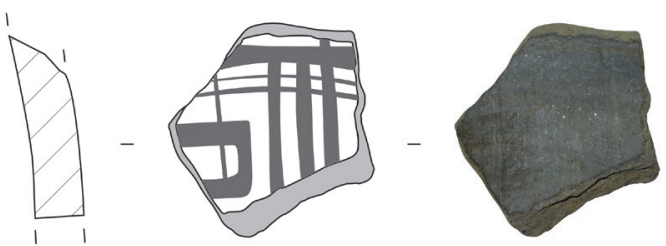

214 [294]

Alcáçova de Santarém

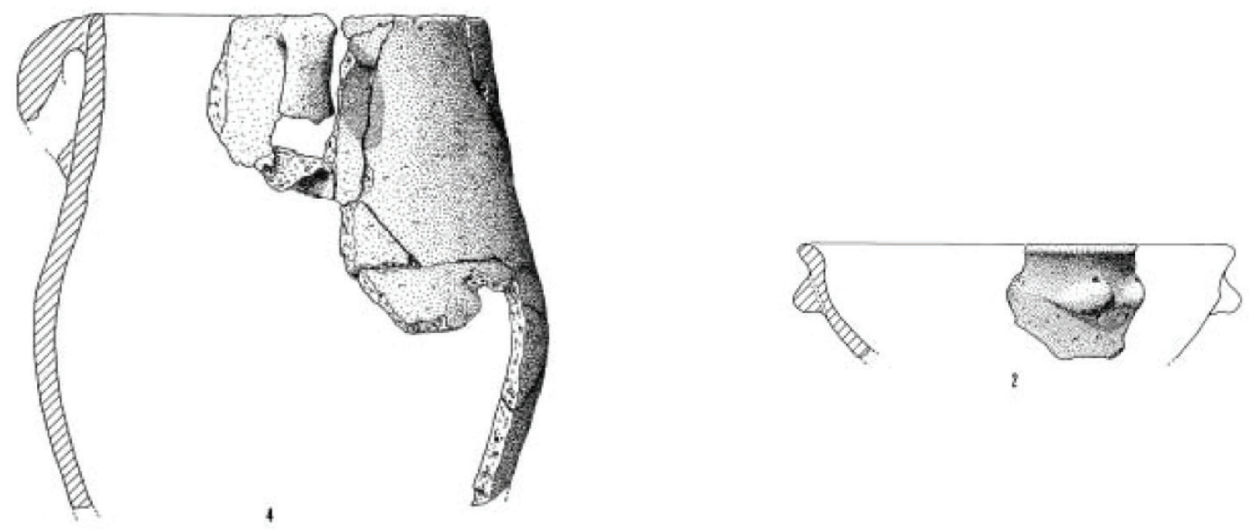

Tapada da Ajuda (Lisboa)

Fig. 2 - Cerâmicas do Bronze Final de Santarém e da Tapada da Ajuda (Lisboa). 
registados na Alcáçova de Santarém (Arruda - Sousa, 2015).

Em muitos destes locais, o trabalho de sílex foi reconhecido, concretamente em elementos de foice, onde, por vezes, é ainda visível o brilho do cereal. É o caso da Tapada da Ajuda (Cardoso 2004), da Quinta Nova de Santo António (Neto et al. 2013) e da Praça da Figueira (Silva 2013), em Lisboa.

As necrópoles são mal conhecidas, havendo dados sobretudo para a margem esquerda do Tejo. O Tanchoal, o Meijão e o Cabeço da Bruxa (Kalb Höck 1980; 1982a; 1982b; 1985; 1988; Vilaça - Cruz - Gonçalves 1999) são cemitérios de incineração em urna, parecendo relevante lembrar que os dois primeiros envolvem o sítio do Alto do Castelo e o último está também próximo deste povoado.

Não pode deixar de referir-se ainda a presença na área em estudo de um conjunto significativo de ocorrências dos chamados "depósitos", certamente votivos e/ou simbólicos, que incorporam quer artefactos metálicos, quer cerâmicas e outros artefactos (Vilaça 2006). Entre os primeiros cabem a espada de Cacilhas (Silva - Gomes 1992), e os conjuntos dos Fiéis de Deus (Melo 2000), do Escaroupim (Senna-Martinez et al. 2013) e do Penedo do Lexim (Arnaud - Oliveira - Jorge 1971) e entre os segundos o da Moita da Ladra (Monteiro - Pereira 2013; Cardoso 2013).

É ainda nesta região que muitos dos artefactos de origem ou inspiração mediterrâneas são incorporados nos contextos locais, que contudo raramente estão presentes nos chamados "depósitos", documentando-se a sua presença apenas no da Moita da Ladra, que se afasta quer quanto ao conteúdo, quer quanto à própria estrutura dos mais clássicos, podendo para ele ser aliás apresentada uma outra interpretação do ponto de vista funcional, mas sempre e ainda votiva. Tratar-se-á, neste caso, mais provavelmente, de uma área onde actividades rituais de tipo potlatch terão ocorrido, o que se propõe com base no tipo de espólio recolhido, muito diversificado (cerâmicas, bronzes), e na abundante fauna mamalógica e malacológica. Parece ser esta a explicação mais plausível para a realidade detectada neste contexto, onde os vasos cerâmicos, estando partidos, puderam reconstituir-se quase integralmente, e estavam associados a espólio metálico, que incorpora escassos artefactos de ferro e outros de bronze, maioritariamente de adorno. Entre estes últimos destacam-se as fíbulas de enrolamento no arco. Por outro lado, estes materiais foram recolhidos em covachos e/ou grandes depressões, numa área que seria extensa e a eles estavam agregados restos faunísticos, o que parece só poder ser explicado no âmbito deste tipo de cerimonial, tal como a antropologia cultural o definiu.

Os restantes depósitos englobam sobretudo machados e espadas (Escaroupim; Fiéis de Deus).

Voltando aos materiais de inspiração mediterrânea, e para além dos da Moita da Ladra, já comentados, registe-se as fíbulas, de cotovelo e de dupla mola, do Abrigo das Bocas (Carreira 1994), Rio Maior, ea peça de bronze de Pragança, com decoração entrançada ou em Y (Lopes - Vilaça 1998; Vilaça 2007), idêntica nas técnicas e padrões decorativos às asas do Pé do Castelo, Beja, e do Monte de São Martinho (Lopes - Vilaça 1998; Vilaça 2007), Castelo Branco, com paralelos na forma e na decoração em exemplares das ilhas do Mediterrâneo Central. Os ponderais de Pragança (Vilaça 2003) correspondem ao maior conjunto de pesos conhecidos em território português, constituindo, quase seguramente, mais do que um jogo, e sendo compatíveis com unidades de peso mediterrâneas. Pesos idênticos foram identificados também no Castro da Ota, no Abrigo das Bocas e na Penha Verde (Vilaça 2003).

O que importa destacar desta ocupação do final da Idade do Bronze é a densidade e a diversidade, reveladoras de uma intensa ocupação e de um grande desenvolvimento de uma região que desempenhou neste momento um importante papel no contacto intercultural que se desenvolveu entre o Atlântico e o Mediterrâneo, sendo óbvio que "determinadas comunidades do Bronze Final participaram em trocas trans-regionais, de longa distância algumas, trocas essas que poderão estar na base da adopção de um determinado peso standart "internacional" dominante na altura" (Vilaça 2003: 276).

\section{A IDADE DO FERRO NO ESTUÁRIO DO TEJO}

Em momento avançado da segunda metade do século VIII a.n.e., em cronologia convencional, o Estuário do Tejo começa a ser frequentado por populações fenícias com origem na área do Estreito de Gibraltar. Este dado está comprovado, pelo menos em Santarém, por datações radiométricas e por materiais (Arruda 1993; 1999-2000) e, em Lisboa, também pelos espólios (Calado et al. 2013; Pimenta Calado - Leitão 2014; Pimenta - Silva - Calado 2014) e ainda pela epigrafia (Zamora Lopez 2013; 2014).

No primeiro dos casos, ficou claro que os níveis da Idade do Ferro inicial se sobrepunham aos do Bronze Final (Arruda - Sousa 2015), 


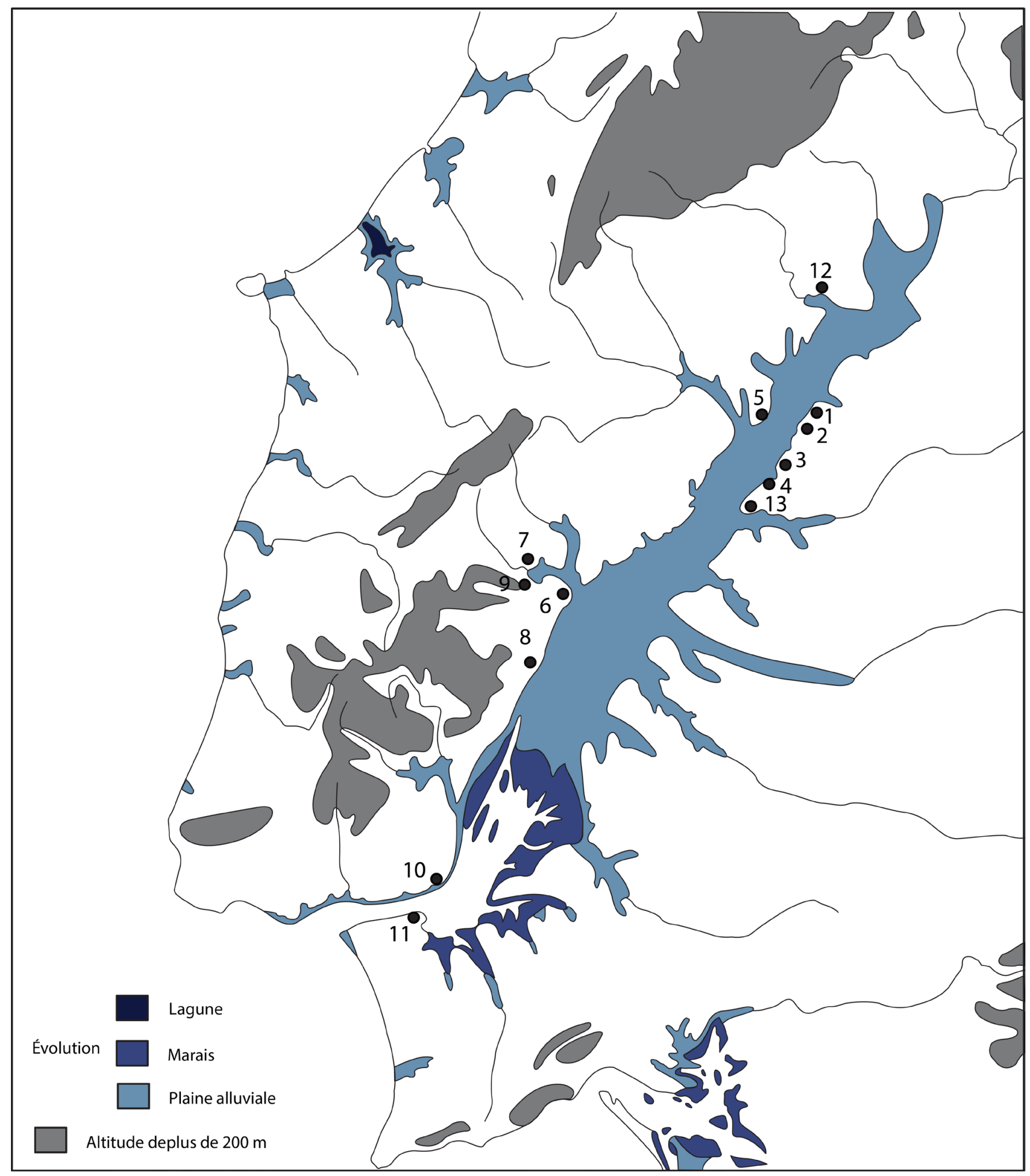

Fig. 3 - Os sítios orientalizantes do estuário do Tejo (VIII-VI a.J.C.): 1 - Alto do Castelo; 2 - Cabeço da Bruxa; 3 - Alto dos Cacos; 4 - Porto do Sabugueiro; 5 - Santarém; 6 - Quinta da Marquesa; 7 - Castro do Amaral; 8 - Santa Sofia; 9 - Quinta da Carapinha; 10 -Lisboa; 11 - Almaraz; 12 - Chões de Alpompé; 13 - Eira da Alorna. 


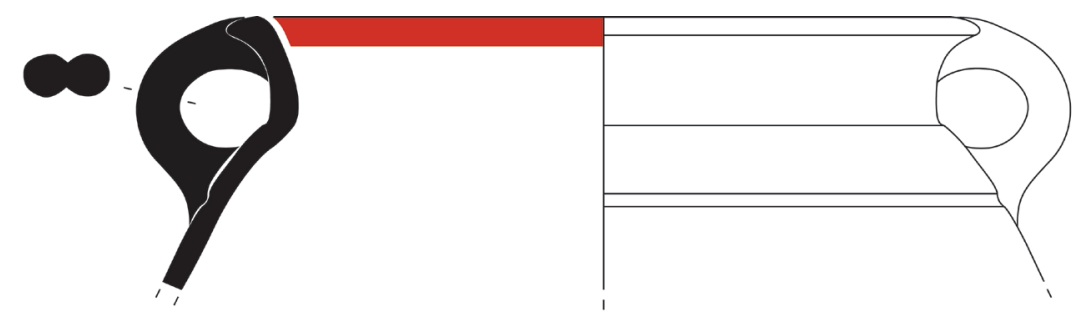

AC $-1407 \mathrm{~V}-\mathrm{I}$

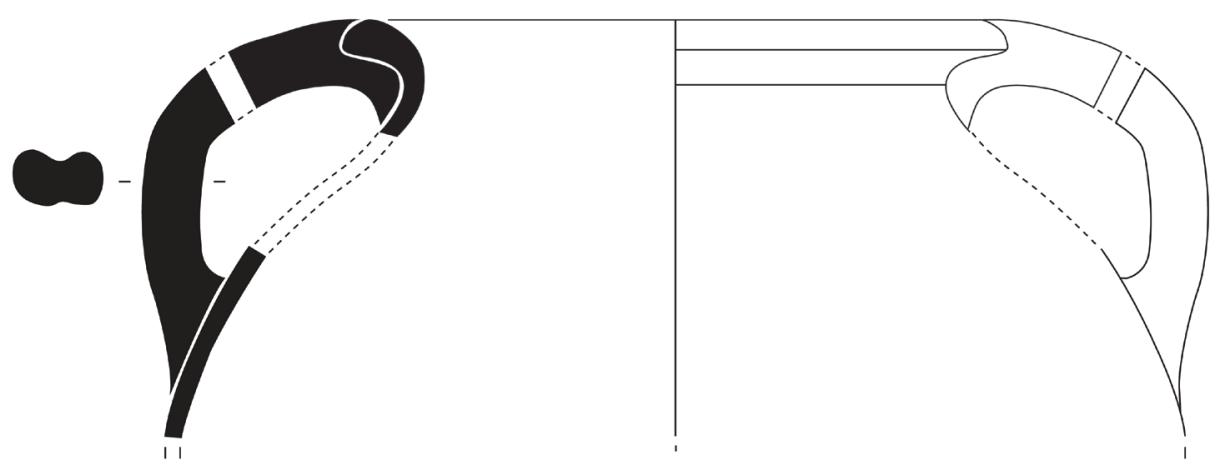

152

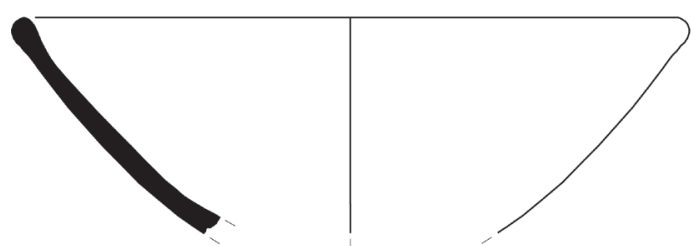

AC 1528-III-I

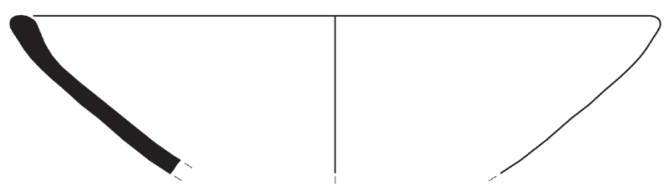

AC $1545-\mathrm{II}-\mathrm{I}$

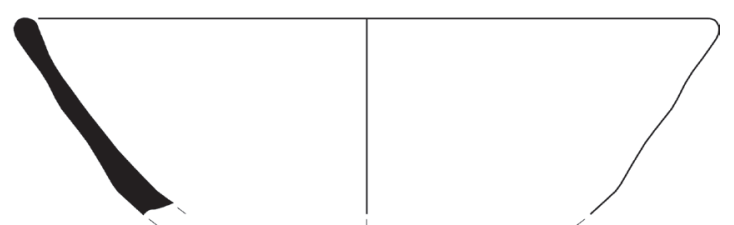

AC 1463.13

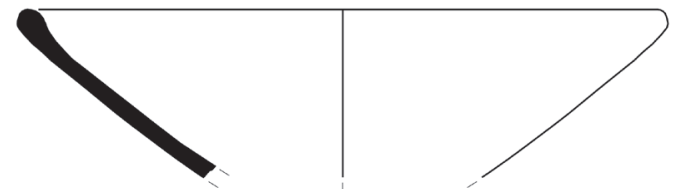

AC 1528 -II-I

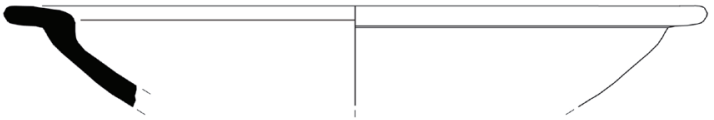

154

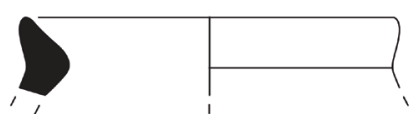

37

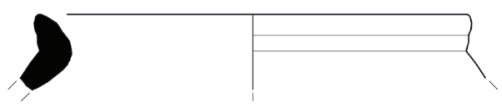

$A C 2$

Fig. 4 - Cerâmicas orientalizantes do Alto do Castelo (pithoi, taças hemisféricas de cerâmica cinzenta, prato de engobe vermelho (?) e ânforas). 

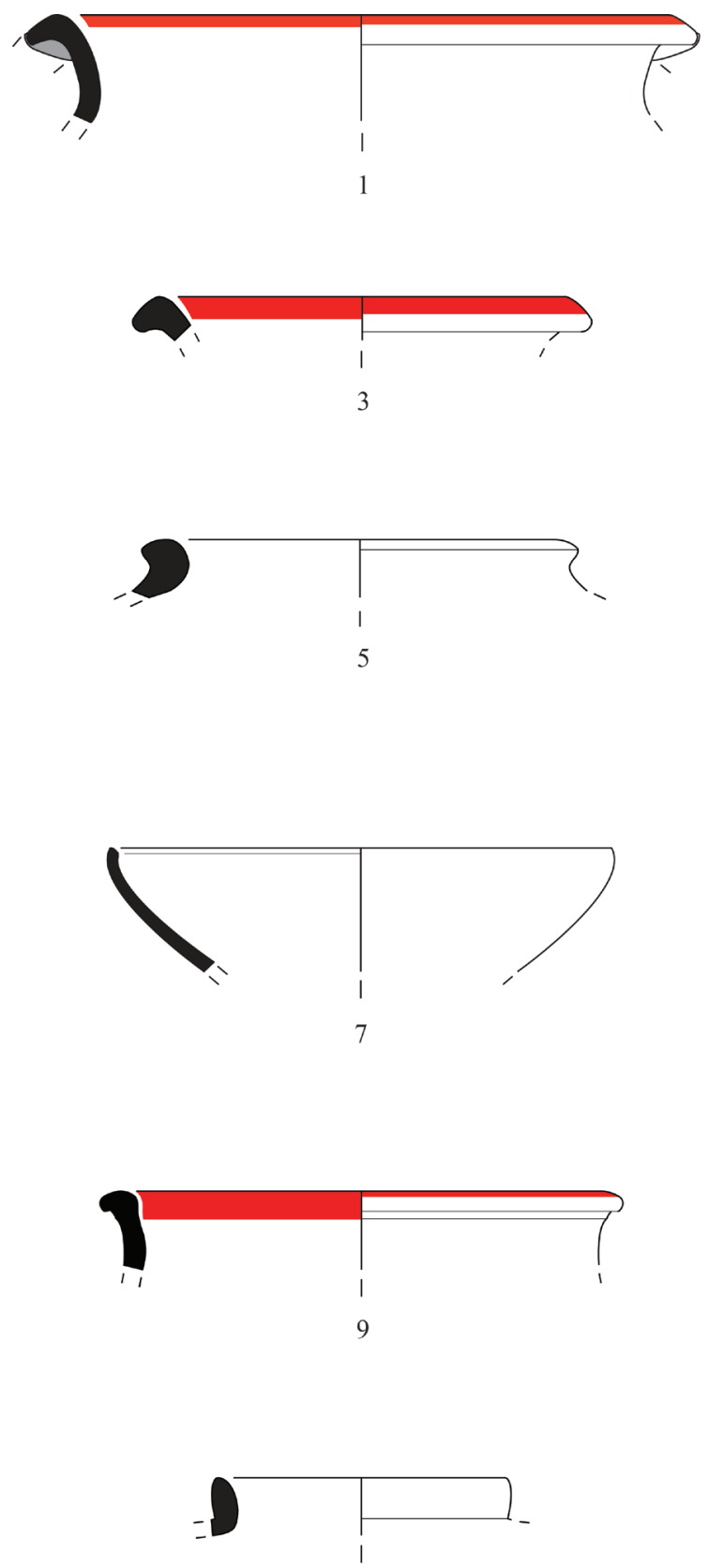

11

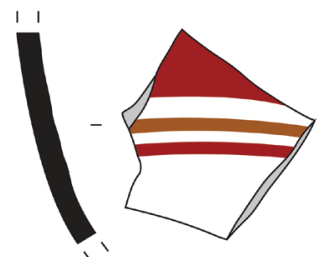

14
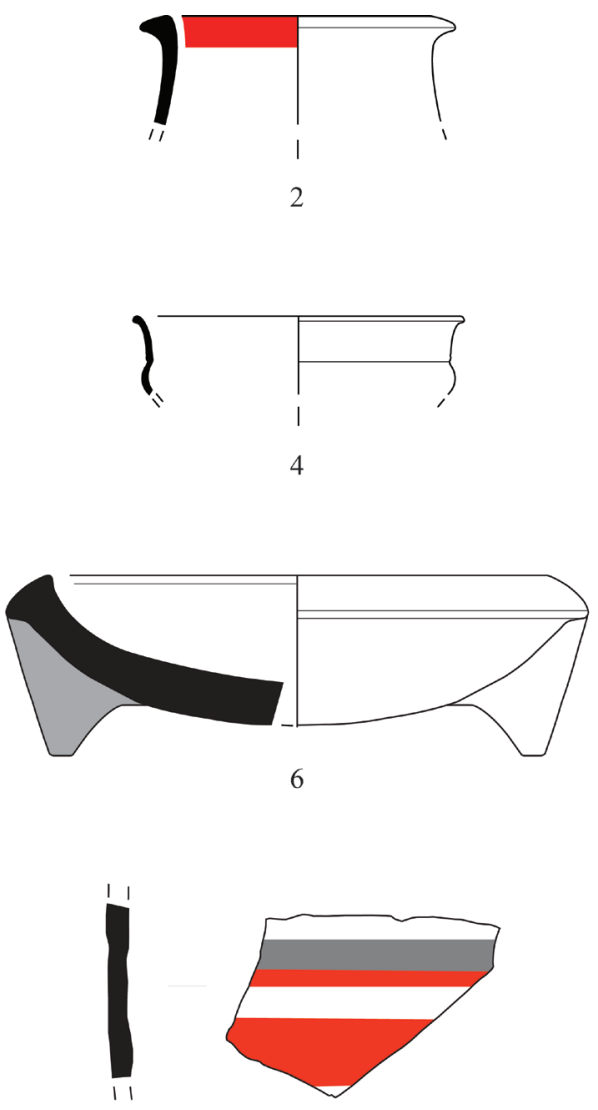

8
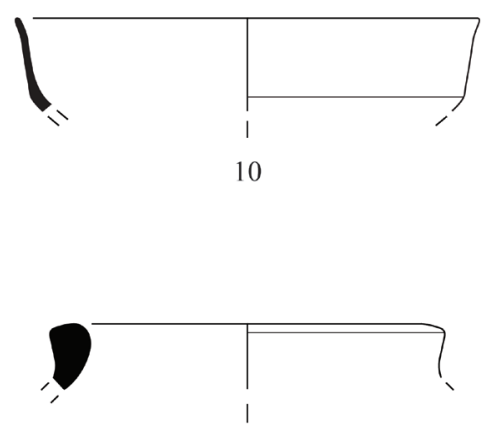

12

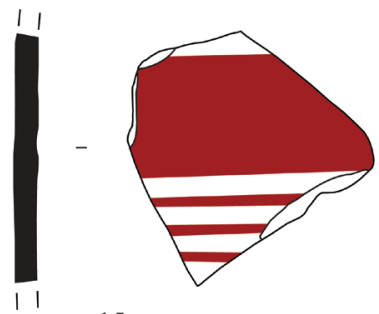

15 $10 \mathrm{~cm}$

Fig. 5 - Cerâmicas orientalizantes de Porto do Sabugueiro (n. ${ }^{\circ}$ 1-8) e do Cabeço da Bruxa (n.॰ 9-15). 
havendo uma clara continuidade de ocupação. Os primeiros mantêm ainda uma alta percentagem (82\%) de cerâmica manual, que contudo já não inclui qualquer fragmento com decoração incisa de tipo Cogotas, sendo que a fabricada a torno inclui pratos e taças de engobe vermelho, ânforas de tipo 10.1.1.1. e cerâmica cinzenta (Arruda 1999-2000; Arruda - Sousa 2015).

Contudo, esta continuidade verificada em Santarém nãoé visível na grande maioria dos restantes sítios, nem nos implantados em cotas altas, nem nos que têm vindo a ser considerados casais agrícolas. Apenas em Almaraz esta sequência tem vindo a ser presumida, sendo de referir desde já que em Lisboa, a ocupação da Idade do Ferro se desenvolveu em altura, na colina do Castelo, ao contrário do que ocorreu durante o Bronze Final, tendo sido na encosta de Santana e na área mais baixa da actual cidade, concretamente na Praça da Figueira, que foram encontrados os vestígios que se lhe associam e que englobam quer materiais, quer estruturas (Silva 2013). Tendo em consideração os espólios da Idade do Ferro e algumas datações de 14C, a cronologia dos primeiros contactos com o mundo mediterrâneo de ambos os sítios da foz do estuário (Barros - Soares 2004) poderá remontar aos finais do século VIII/ primeira metade do VII a.n.e., portanto, um pouco mais tardia do que a de Santarém. Também o grafito identificado em Lisboa nas escavações do Castelo de São Jorge há já alguns anos aponta para a mesma cronologia (Zamora Lopez 2014).

Entre o século VII e o século VI a.n.e., a ocupação desenvolveu-se nas margens do Estuário, fundando-se novos sítios de raiz, quer na margem esquerda, como Cabeço da Bruxa, em Alpiarça, Porto do Sabugueiro, em Muge, Salvaterra de Magos (Pimenta - Mendes 2008; 2013; Pimenta et al. 2014) e Quinta da Alorna, em Almeirim, quer na direita, Santa Sofia e Quinta da Marquesa (Pimenta - Mendes 20102011). Para além de Santarém, Lisboa e Almaraz, outros sítios do Bronze Final, Alto do Castelo, Alpiarça (Arruda et al. no prelo), Castro do Amaral, Alenquer, e, eventualmente, o Alto dos Cacos, Almeirim (Pimenta - Henriques - Mendes 2012) são também então ocupados, mesmo que essas ocupações não estejam ainda bem definidas, em termos cronológicos.

Mas também parece certo que todos os restantes são abandonados, concretamente os que se localizam no hinterland, quer os de altura quer os de planície.

Os sítios fundados ex nihilo, na margem do rio, em torno ao século VII/VI a.n.e., apresentam características muito específicas, que importa destacar. Ao contrário dos de altura, com ocupação anterior, estes, ribeirinhos, são sempre de baixa altitude, implantando-se em áreas com poucas descontinuidades altimétricas, entre os 5,5 e os 8 metros. Em alguns deles, os materiais estão dispersos por uma superfície consideravelmente extensa. A fertilidade da planície aluvial do Tejo justifica a intensa e extensa exploração agrícola dos terrenos onde estes sítios se implantaram, situação que teve grandes impactos sobre o subsolo, que é constituído por sedimentos de matriz arenosa, o que dificultou também a conservação dos níveis de ocupação. Esta realidade, que pudemos observar durante os trabalhos de campo que efectuámos em 2013 no Cabeço da Bruxa e no Porto do Sabugueiro, pode justificar a dispersão dos espólios, sendo ainda responsável pelo elevado grau de destruição que os sítios apresentam.

Foram os materiais, ainda que quase sempre recolhidos em contextos secundários, que permitiram avançar com a cronologia do século VII/VI a.n.e, para a fundação destes sítios da margem esquerda do Tejo. Para Porto do Sabugueiro, os pithoi, a urna Cruz del Negro, as ânforas, os pratos e taças de engobe vermelho e os vasos trípodes (Pimenta - Mendes 2008; Pimenta et al. 2014) fornecem contornos mais específicos ao escaravelho e escarabóide recolhidos no sítio na década de 30 do século XX (Pereira 1975; Almagro Gorbea - Torres Ortiz 2009). Menos abundantes e menos diversificados tipologicamente são os materiais do Cabeço da Bruxa, mas o conjunto inclui também ânforas (10.1.2.1.) e pithoi. O mesmo universo é visível no Alto dos Cacos e na Quinta da Alorna.

\section{DISCUSSÃO}

A ocupação da I Idade do Ferro desenvolveuse, portanto, exclusivamente ao longo da orla do rio, desprezando-se os territórios do interior.

Esta ocupação das margens, que, em certos troços, corresponde a uma verdadeira rede de povoamento, tem de ser interpretada em função do próprio rio como via de comunicação que dá acesso ao interior. De facto, se é verdade que os solos são particularmente férteis nesta área, como é visível ainda hoje em dia, a verdade é que as várzeas são ainda mais férteis.

Por outro lado, é necessário fazer notar que, pelo menos na área norte do estuário, o povoamento se torna ainda mais estratificado. Com efeito, os sítios 
da margem são maioritariamente de escassa altura, ainda que de todos eles Santarém se torne visível.

Parece ainda importante dizer que a situação que se pode detectar na área do antigo Estuário do Tejo indicia uma alteração significativa no modelo de ocupação do território, que certamente decorreu de uma mudança na estrutura económica, social e política que a chegada de fenícios à região implicou. A verdade é que há uma ruptura, que não é exclusivamente tecnológica. E se num primeiro momento se poderia falar até de resistência, mesmo que adaptativa, de que os depósitos poderiam ser exemplos, como já defendeu para este e outros contextos Raquel Vilaça (2006), a verdade é que certamente no Estuário do Tejo, como em muito outros espaços coloniais, o processo, apesar de certamente negociado, provocou rupturas e descontinuidades na estratégia de povoamento e naturalmente em termos tecnológicos, mas que são também visíveis na adopção de novos padrões alimentares e na própria paisagem. Recordemos, a este propósito que, no mesmo momento, a vinha domesticada é introduzida, a floresta dá lugar a espaços mais abertos, aumentando a área cultivada (Arruda 2003), e a galinha foi registada em Santarém (Davis 2006).

$\mathrm{Na} 1^{\mathrm{a}}$ metade do $1^{\circ}$ milénio a.n.e. os encontros culturais que tiveram lugar nesta área criaram um novo sistema, onde o elemento indígena parece perder protagonismo, mesmo que tenha participado, de forma mais ou menos pró-activa, no processo. O poder passa a emanar dos sítios que se orientalizaram, onde a população de origem mediterrânea se instalou, tendo a maioria dos povoados indígenas sido abandonados. Esta realidade, que os dados empíricos proporcionaram, não cabe nos modelos "pacifistas" e "integradores" dos paladinos do póscolonialismo. É verdade que esta é uma região onde o Mediterrâneo não é uma novidade absoluta, onde há, no Bronze Final, elementos que evidenciam fortes ligações a universos económicos, culturais e simbólicos exógenos, de que os pesos de balança são um muito bom exemplo, não podendo esquecerse que a adopção dos sistemas de pesos orientais obrigou, certamente, à assimilação de processos de racionalização e abstracção, como já recordou M. Ruiz-Gálvez (1998). Contudo, "...os ponderais não são sinónimo de centros comerciais e de normas de mercado, nem, tão pouco, de uma utilização prática efectiva...No Bronze Final do Ocidente Peninsular, não há palácios, não há mercados, não há templos....", como recordou muito bem a professora de Coimbra
(Vilaça 2003). A adaptação a um novo modelo de organização social e política, que a colonização fenícia implicou, foi certamente "dolorosa" e em muitos casos não inclusiva, mesmo que para alguns tenha tido evidentes benefícios.

\section{REFERÊNCIAS BIBLIOGRÁFICAS}

ALMAGRO GORBEA, M. - TORRES ORTIZ, M. (2009) Los escarabeos fenícios de Portugal. Un estado de la cuestión. Estudos Arqueológicos de Oeiras 17: 521-554. ARNAUD, J. - OLIVEIRA, V. S. - JORGE, V. O. (1971) - O povoado fortificado neo e eneolítico do Penedo do Lexim (Mafra): campanha preliminar de escavações (1970). O Arqueólogo Português 3-5: 97-132.

ARRUDA, A. M. (1993) - A ocupação da Idade do Ferro da Alcáçova de Santarém no contexto da expansão fenícia para a fachada atlântica peninsular. Estudos Orientais 4: 193-214.

ARRUDA, A. M. (1999-2000) - Los Fenicios en Portugal. Fenicios y mundo indígena en el centro y sur de Portugal (siglos VIII-VI a.C.). Barcelona.

ARRUDA, A. M. (2003) - Contributo da colonizaçãoo fenícia para a domesticaçãoo da terra portuguesa. In Ecohistoria del paisaje agrário - la agricultura feníciopúnica en el Mediterráneo. Valência: 205-217.

ARRUDA, A. M. (2005a) - $01^{\circ}$ milénio a.n.e. no Centro e no Sul de Portugal: leituras possíveis no início de um novo século. O Arqueólogo Português 4-23: 9-156. ARRUDA, A. M. (2005b) - Orientalizante e pósorientalizante no sudoeste peninsular: geografia e cronologias. In Actas del III Simposio Internacional de Arqueología de Mérida: Protohistoria del Mediterráneo Occidental. Mérida: 277-303.

ARRUDA, A. M. - SOUSA, E. (2015) - Late Bronze Age in Alcáçova de Santarém (Portugal). Trabajos de Prehistoria 72-1: 176-187.

ARRUDA, A. M. - SOUSA, E. - PIMENTA, J. - MENDES, H. - SOARES, R. (2014) - Alto do Castelo's Iron Age occupation (Alpiarça, Portugal). Zephyrus 74: 143-155. BARBOSA, E. (1956) - O Castro da Ota (Alenquer). O Arqueólogo Português 3: 117-124.

BARROS, L. (1998) - Introdução à Pré e à Proto-História de Almada. Almada.

BARROS, L. - SOARES, A. M. (2004) - Cronologia absoluta para a ocupação orientalizante da Quinta do Almaraz no estuário do Tejo (Almada, Portugal). $O$ Arqueólogo Português 4-22: 333-325.

BOAVENTURA, R. - PIMENTA, J. - VALLES, E. (2013) O povoado do Bronze Final do Castelo da Amoreira (Odivelas). Estudos Arqueológicos de Oeiras 20: 623640. 
CALADO, M. - ALMEIDA, L. - LEITÃO, V. - LEITÃO, M. (2013) - Cronologias absolutas para a la Idade do Ferro em Olisipo - o exemplo de uma ocupação em ambiente cársico na actual Rua da Judearia em Alfama. Cira Arqueologia 2: 118-132.

CARDOSO, J. L. (1997-1998) - O povoado do Bronze Final do Castelo dos Mouros. Estudos Arqueológicos de Oeiras 7: 169-177.

CARDOSO, J. L. (2004) - A Baixa Estremadura dos finais do IV milénio a.C. até à chegada dos romanos: um ensaio de História Regional. Oeiras.

CARDOSO, J. L. (2013) - Moita da Ladra 2 (Vila Franca de Xira): um sítio ritual do Bronze final da região de Lisboa. Revista da Faculdade de Letras ciências e técnicas do património 12: 49-67.

CARDOSO, J. L. (2010-2011a) - O casal agrícola do Bronze Final de Abrunheiro (Oeiras). Estudos Arqueológicos de Oeiras 18: 33-74.

CARDOSO, J. L., ROQUE, J. - PEIXOTO, F. - FREITAS, F. (1980-1981) - Descoberta de jazida da Idade do Bronze da Tapada da Ajuda. Setúbal Arqueológica 6-7: 117-147.

CARDOSO. J. L. - SILVA, I. M. (2004) - O povoado do Bronze Final da Tapada da Ajuda (Lisboa): estudo do espólio cerâmico. Revista Portuguesa de Arqueologia 7-1: 227-271.

CARREIRA, J. R. (1994) - A Pré-História recente do Abrigo Grande das Bocas, Rio Maior. Trabalhos de Arqueologia da EAM 2: 47-144.

DAVIS, S. (2006) - Faunal remains from Alcáçova de Santarém, Portugal. Lisboa.

KALB, P. - HÖCK, M. (1980) - Cabeço da Bruxa, Alpiarça (Distrikt Santarém). Vorbericht uber die Grabung im Januar und Februar 1979. Madrider Mitteilungen 21: 91-104.

KALB, P. - HÖCK, M. (1982a) - Alto do Castelo, Alpiarça, Distrikt Santarém. Vorbericht über die grabung 1981. Madrider Mitteilungen 23: 145-151.

KALB, P. - HÖCK, M. (1982b) - Cabeço da Bruxa, Alpiarça (Distrito de Santarém). Relatório preliminar da escavação de Janeiro e Fevereiro de 1979. Portugalia 2-3: 61-70.

KALB, P. - HÖCK, M. (1985) - Cerâmica de Alpiarça. Catálogo. Alpiarça.

KALB, P. - HÖCK, M. (1988) - O povoamento préhistórico de Alpiarça. Arqueologia 17: 193-200.

LOPES. M. C. - VILAÇA, R. (1998) - Peça do Bronze Final proveniente do Pé do Castelo (Trindade, Beja). Arquivo de Beja 3-7/8: 63-84.

MADEIRA, J. - GONÇALVES, J. L. - RAPOSO, L. PARREIRA, R. (1972) - Achados da Idade do Bronze no Monte da Pena (Barro / Torres Vedras) - Notícia Prévia.
O Arqueólogo Português 3-6: 207-212.

MARQUES, G. (1987) - Aspectos da Proto-História do território Português III - Castelo da Amoreira (Odivelas, Loures). Boletim Cultural 1: 51-58.

MATIAS, C. (2004) - Serra do Socorro: uma aproximação à sua caracetrização arqueológica no contexto da Estremadura atlântica. Boletim Cultural de Mafra: 308358.

MELO, A. (2000) - Armas, utensílios e esconderijos. Alguns aspectos da metalurgia do Bronze Final: o depósito do Casal dos Fiéis de Deus. Revista Portuguesa de Arqueologia 3-1: 15-120.

MONTEIRO, M. - PEREIRA, A. (2013) - Um depósito votivo da Idade do Bronze na Moita da Ladra (Vila Franca de Xira): Síntese dos trabalhos realizados e resultados preliminares. Cira - Arqueologia 2: 63-94. NETO, N. - GONZALEZ, C. - REBELO, P. - SANTOS, R. ROCHA, M. (2013) - Trabalhos arqueológicos na Quinta Nova de Santo António ou dos Ingleses - Carcavelos. A ocupação do Bronze final. Cira - Arqueologia 2: 1939.

PEREIRA, M. A. H. (1975) - Objectos Egípcios do Porto do Sabugueiro (Muge). Conimbriga 14: 173-176.

PIMENTA, J. - CALADO, M. - LEITÃO, M. (2014) - Novos dados sobre a ocupação pré-romana da cidade de Lisboa. A intervenção da Rua de São João da Praça. In ARRUDA, A. M. (ed.), Fenícios e púnicos, por terra e por mar. Actas do VI Congresso Internacional de Estudos Fenícios e Púnicos. Lisboa: 712-723.

PIMENTA, J. - SILVA, R. B. - CALADO, M. (2014) - Sobre a ocupação pré-romana de Olisipo: a intervenção arqueológica urbana da Rua de São Mamede ao Caldas n.015. In ARRUDA, A. M. (ed.), Fenícios e púnicos, por terra e por mar. Actas do VI Congresso Internacional de Estudos Fenícios e Púnicos. Lisboa: 724-735.

PIMENTA, J. - MENDES, H. (2010-2011) - Novos dados sobre a presença fenícia no vale do Tejo. As recentes descobertas na área de Vila Franca de Xira. Estudos Arqueológicos de Oeiras 18: 591-618.

PIMENTA, J. - HENRIQUES, E. - MENDES, H. (2012) - O Acampamento romano de Alto dos Cacos. Almeirim.

PIMENTA, J. - MENDES, H. (2013) - 1. a Campanha de escavações arqueológicas no povoado pré-romano de Porto do Sabugueiro - Muge - Salvaterra de Magos. Cira - Arqueologia 2: 195-219.

PIMENTA, J. - MENDES, H. (2008) - Descoberta do povoado pré-romano do Porto do Sabugueiro, Muge. Revista Portuguesa de Arqueologia 11-2: 171-194.

PIMENTA, J. - MENDES, H. - ARRUDA, A. M. - SOUSA, E. - SOARES, R. (2014) - Do pré-romano ao Império: a ocupação humana do Porto do Sabugueiro (Muge, Salvaterra de Magos). Magos 1: 39-58. 
PINTO, C. V. - PARREIRA, R. (1978) - Contribuição para o estudo do Bronze Final e do Ferro Inicial a norte do Estuário do Tejo. In Actas das III Jornadas da Associação dos Arqueólogos Portugueses. Lisboa: 147-163.

PONCE, M. (2013) - O Bronze Final na Península de Lisboa. O caso do Cabeço de Alcainça na transição entre o $2^{\circ}$ e o $1^{\circ}$ milénio a.C. Dissertação de Mestrado apresentada à Faculdade de Letras da Universidade de Lisboa.

RUIZ-GÁLVEZ PRIEGO, M. (1998) - La Edad del Bronce en la Europa Atlántica. Un viaje a los orígenes de Europa Occidental. Barcelona.

SENNA-MARTINEZ, J. C. - LUÍS, E. - REPREZAS, J. LOPES, F. - FIGUEIREDO, E. - ARAÚJO, M. F. - SILVA, R. J. C. (2013) - Os machados Bujões/Barcelos e as origens da metalurgia do bronze na fachada atlântica peninsular. In ARNAUD, J. M. - MARTINS, A. - NEVES, C. (eds.), Arqueologia em Portugal, 150 Anos. Lisboa: 591-600.

SILVA, A. C. F. - GOMES, M. V. (1992) - Proto-História de Portugal. Lisboa.

SILVA, R. B. (2013) - A ocupação da idade do bronze final da Praça da Figueira (Lisboa): novos e velhos dados sobre os antecedentes da cidade de Lisboa. Cira-Arqueologia 2: 40-102.

VASCONCELLOS, J. L. (1915) - História do Museu Etnológico Português (1893-1914). Lisboa.
VILAÇA, R. (2003) - Acerca da existência de ponderais em contextos do Bronze Final / Ferro Inicial no território português. O Arqueólogo Português 4-21: 245-288.

VILAÇA, R. (2006) - Depósitos de Bronze no território português. Um debate em aberto. O Arqueólogo Português 4-24: 9-150.

VILAÇA, R. (2007) - Todos os caminho vão dar ao Ocidente: trocas e contactos no Bronze Final. Estudos Arqueológicos de Oeiras 15: 135-154.

VILAÇA, R. - ARRUDA, A. M. (2004) - Ao longo do Tejo, do Bronze ao Ferro. Conímbriga 43: 11-45.

VILAÇA, R. - CRUZ, D. - GONÇALVES, H. (1999) A necrópole de Tanchoal dos Patudos (Alpiarça, Santarém). Conímbriga 38: 5-29.

ZAMORA LOPEZ, J. A. (2013) - Novedades de epigrafía fenicio-púnica en la Península Ibérica y sus aledaños. Palaeohispanica 13: 359-384.

ZAMORA LOPEZ, J. A. (2014) - Palabras fluidas en el extremo Occidente. Sobre un nuevo grafito fenicio, hallado en la desembocadura del Tajo, que recoge un posible topónimo local". In BÁDENAS DE LA PEÑA, P. - CABRERA BONET, P. - MORENO CONDE, M. RUIZ RODRÍGUEZ, A. - SÁNCHEZ FERNÁNDEZ, C. TORTOSA ROCAMORA, T. (eds.), Homenaje a Ricardo Olmos. Per speculum in aenigmate. Madrid: 306-314. 


\section{OPHIUSSA}

\section{POLÍTICA EDITORIAL}

A Ophiussa - Revista do Centro de Arqueologia da Universidade de Lisboa foi iniciada sob a direcção de Victor S. Gonçalves em 1996, tendo sido editado o volume 0. O volume 1 (2017) é uma edição impressa e digital da UNIARQ - Centro de Arqueologia da Universidade de Lisboa.

O principal objectivo desta revista é a publicação e divulgação de trabalhos com manifesto interesse, qualidade e rigor científico sobre temas de Pré-História e Arqueologia, sobretudo do território europeu e da bacia do Mediterrâneo.

A Ophiussa - Revista do Centro de Arqueologia da Universidade de Lisboa publicará um volume anual. A partir de 2018, os artigos submetidos serão sujeitos a um processo de avaliação por parte de revisores externos (peer review). O período de submissão de trabalhos decorrerá sempre no primeiro trimestre e a edição ocorrerá no último trimestre de cada ano.

A revista divide-se em duas secções: artigos científicos e recensões bibliográficas. Excepcionalmente poderão ser aceites textos de carácter introdutório, no âmbito de homenagens ou divulgações específicas, que não serão submetidos à avaliação por pares. Isentas desta avaliação estão também as recensões bibliográficas.

Todas as submissões serão avaliadas, em primeira instância, pela Coordenação Editorial, no que respeita ao seu conteúdo formal e à sua adequação face à política editorial e às normas de edição da revista. Os trabalhos que cumprirem estes requisitos serão posteriormente submetidos a um processo de avaliação por pares cega / blind peer review (mínimo de dois revisores). O Conselho Científico, constituído pela direcção da UNIARQ e por investigadores externos, seleccionará os revisores e acompanhará o processo de edição.

Esta etapa será concretizada por investigadores externos qualificados, sendo os respectivos pareceres entregues num período não superior a três meses. Os revisores procederão à avaliação de forma objectiva, tendo em vista a qualidade do conteúdo da revista; as suas críticas, sugestões e comentários serão, na medida do possível, construtivos, respeitando as capacidades intelectuais do(s) autor(es). Após a recepção dos pareceres, o(s) autor(es) tem um prazo máximo de um mês para proceder às alterações oportunas e reenviar o trabalho.

A aceitação ou recusa de artigos terá como únicos factores de ponderação a sua originalidade e qualidade científica. $\mathrm{O}$ processo de revisão é confidencial, estando assegurado o anonimato dos avaliadores e dos autores dos trabalhos, neste último caso até à data da sua publicação.

Os trabalhos só serão aceites para publicação a partir do momento em que se conclua o processo da revisão por pares. Os textos que não forem aceites serão devolvidos aos seus autores.

O conteúdo dos trabalhos é da inteira responsabilidade do(s) autor(es) e não expressa a posição ou opinião do Conselho Científico ou da Coordenação Editorial.

As ilustrações que não sejam do(s) autor(es) devem indicar a sua procedência. O Conselho Científico e a Coordenação Editorial assumem que os autores solicitaram e receberam autorização para a reprodução dessas ilustrações, e, como tal, rejeitam a responsabilidade do uso não autorizado das ilustrações e das consequências legais por infracção de direitos de propriedade intelectual.

A publicação de textos na Ophiussa - Revista do Centro de Arqueologia da Universidade de Lisboa não implica o pagamento de qualquer taxa nem dá direito a qualquer remuneração económica.

Os textos propostos para publicação devem ser inéditos e não deverão ter sido submetidos a qualquer outra revista ou edição electrónica. Aceitam-se trabalhos redigidos em português, inglês, espanhol, italiano e francês.

Esta edição disponibiliza de imediato e gratuitamente a totalidade dos seus conteúdos, em acesso aberto, de forma a promover, globalmente, a circulação e intercâmbio dos resultados da investigação científica e do conhecimento.

Esta publicação dispõe de uma versão impressa, a preto e branco, com uma tiragem limitada, que será distribuída gratuitamente pelas bibliotecas e instituições mais relevantes internacionalmente, e intercambiada com publicações periódicas da mesma especialidade, que serão integradas na Biblioteca da Faculdade de Letras da Universidade de Lisboa. Conta, paralelamente, com uma versão digital, a cores, disponibilizada no endereço www.ophiussa.letras.ulisboa.pt, onde se pode consultar a totalidade da edição.

Para mais informações contactar: uniarq@letras.ulisboa.pt 


\section{OPHIUSSA}

\section{EDITORIAL POLICY}

Ophiussa - Revista do Centro de Arqueologia da Universidade de Lisboa started under the direction of Victor S. Gonçalves in 1996, with the edition of volume 0. Volume 1 (2017) is a printed and digital edition of UNIARQ - Centro de Arqueologia da Universidade de Lisboa.

The main objective of this journal is the publication and dissemination of papers of interest, quality and scientific rigor concerning Prehistory and Archeology, mostly from Europe and the Mediterranean basin.

Ophiussa - Revista do Centro de Arqueologia da Universidade de Lisboa will publish an annual volume. From 2018, submitted articles will be subject to a peer-review evaluation process. The submission period will always occur in the first quarter of each year and the edition will occur in the last quarter.

The journal is divided into two sections: scientific articles and bibliographic reviews. Exceptionally, texts of an introductory nature may be accepted, in the context of specific tributes or divulgations, which will not be submitted to peerreview evaluation. Exemptions from this evaluation are also the bibliographic reviews.

All submissions will be considered, in the first instance, by the Editorial Board, regarding its formal content and adequacy in face of the editorial policy and the journal's editing standards. Papers that meet these requirements will subsequently be submitted to a blind peer-review process (minimum of two reviewers). The Scientific Council, constituted by the directors of UNIARQ and external researchers, will select the peer-reviewers and follow the editing process.

This stage will be carried out by qualified external researchers, and their feedback will be delivered within a period of no more than two months. The reviewers will carry out the evaluation in an objective manner, in view of the quality and content of the journal; their criticisms, suggestions and comments will be, as far as possible, constructive, respecting the intellectual abilities of the author (s). After receiving the feedback, the author(s) has a maximum period of one month to make the necessary changes and resubmit the work.

Acceptance or refusal of articles will have as sole factors of consideration their originality and scientific quality. The review process is confidential, with the anonymity of the evaluators and authors of the works being ensured, in the latter case up to the date of its publication.

Papers will only be accepted for publication as soon as the peer review process is completed. Texts that are not accepted will be returned to their authors.

The content of the works is entirely the responsibility of the author(s) and does not express the position or opinion of the Scientific Council or Editorial Board.

Illustrations that are not from the author(s) must indicate their origin. The Scientific Council and Editorial Board assume that the authors have requested and received permission to reproduce these illustrations and, as such, reject the responsibility for the unauthorized use of the illustrations and legal consequences for infringement of intellectual property rights.

The publication of texts in Ophiussa - Revista do Centro de Arqueologia da Universidade de Lisboa does not imply the payment of any fee nor does it entitle to any economic remuneration.

Texts proposed for publication must be unpublished and should not have been submitted to any other journal or electronic edition. Works written in Portuguese, English, Spanish, Italian and French are accepted.

This edition immediately and freely provides all of its content, in open access, in order to promote global circulation and exchange of scientific research and knowledge.

This publication has a limited printed edition in black and white, which will be distributed free of charge by the most relevant international libraries and institutions, and exchanged with periodicals of the same specialty, which will be integrated in the Library of Faculdade de Letras of Universidade de Lisboa. It also has a digital version, in color, available at address www. ophiussa.letras.ulisboa.pt, where one can consult the entire edition.

For more information contact: uniarq@letras.ulisboa.pt 


\section{OPHIUSSA}

REVISTA DO CENTRO DE ARQUEOLOGIA DA UNIVERSIDADE DE LISBOA

\section{1 - 2017}

\section{ÍNDICE}

VICTOR S. GONÇALVES - Ophiussa regressa, em digital e, logo de seguida, em papel .... MARCO ANTÓNIO ANDRADE - O sítio pré-histórico do Sobral do Martim Afonso (Sätuatterra de Magos, Portugal): um curioso contexto do Neolítico Final / Calcolítico na marégentesquerda do Baixo Tejo

ANA CATARINA SOUSA - JORGE LOPES - O sítio do Moinho do Custódio (tarruda dos vinthost.

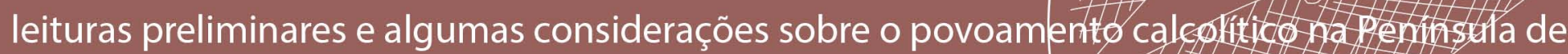
Lisboa

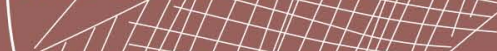
51

PEDRO ALBUQUERQUE - O Guadiana como fronteira? Notas para un profecto-de investigação

ANA MARGARIDA ARRUDA - ELISA DE SOUSA - JOÃO PIMENTA - RUI SOARES - HENRIQU MENDES - Fenícios e indígenas em contacto no Estuário do Tejo

ELISA DE SOUSA - Algumas reflexões sobre a fase tardia da Idade do Ferro no Ocidente Atlântico

CARLOS PEREIRA - Produção e comércio de lucernas durante a Antiguidade Tardia: génese e evolução das lucernas tardo-antigas de produção africana

JACINTA BUGALHÃO - O papel da mulher na Arqueologia Portuguesa

RUI BOAVENTURA - VERA.LEISNER@PORTUGAL.PT

RECENSÕES BIBLIOGRÁFICAS - Estudos Arqueológicos de Oeiras, 22 volumes e a contar... (VICTOR S. GONÇALVES) 